\title{
GLOBAL INEQUITY IN SCIENTIFIC NAMES AND WHO THEY HONOR
}

${ }^{1}$ Department of Ecology and Evolutionary Biology and Museum of Zoology, University of

4 Michigan, Ann Arbor, MI, USA

$5 \quad{ }^{2}$ Department of Animal and Plant Sciences, University of Sheffield, Sheffield, UK

$6{ }^{3}$ Committee on Evolutionary Biology, University of Chicago, Chicago, IL, USA

$7 \quad{ }^{4}$ Field Museum of Natural History, Chicago, IL, USA

*for correspondence: dubaysg@umich.edu, d.h.palmer@sheffield.ac.uk, npiland@uchicago.edu

KEY WORDS: birds, colonialism, eponyms, global North, global South, imperialism, inequity, power structures, taxonomy, Western science

\section{ABSTRACT}

Linnaean taxonomy is a cornerstone of Western biology in which organisms are given a twopart name (a genus and species), creating biological units that help us order and manage our knowledge of the living world. In this system, the names of species themselves take on additional functions, such as describing features of the organism or honoring individuals (known as eponyms). Here, we interrogate how power and authority over the natural world are claimed through Western scientific naming practices to evaluate the legacies of imperialism, dispossession, and exclusion in these practices. We compile and analyze a dataset of all bird species descriptions from 1950 to present, asking: who has access and power to name species, and who is honored in species names? We show that $95 \%$ of newly described species are described from the global South, but the majority of species and eponyms are described by authors, and named after individuals, from the global North. We find an increase through time in authors from the global South, which is associated with a rise in eponyms that honor individuals from global South countries. However, this formal inclusion of global South authors has not translated into increases in first authorship (a primary form of credit and authority in Western science). We contextualize these disparities in naming and authorship within broader global structures of access and power put in place through centuries of European and U.S. imperialism, but a historical perspective alone ignores institutional and individual agency and incentives in present-day actions. As we increasingly reflect on the social foundations and impacts of our science, these findings show how research and labor in the global South continue to be disproportionately translated into power and authority in the global North, upholding and re-enacting imperial structures of domination.

For working definitions of key terms, see the Definitions Box at the end of the text. For Spanish language version of the manuscript, see Supplement (para la versión en español ver

35 Suplemento). 


\section{INTRODUCTION}

The act of naming and ordering the living world cuts across cultures and language, and is an integral part of how we make sense of the world around us (Brown 1984, Atran 1998, Berlin 2014). By naming and classifying organisms, we build a foundation for understanding their biology, which has enabled scientists to study variation and diversity (Darwin 1859), define biological units to conserve (Mace and Lande 1990, Myers et al. 2002), and commodify or extirpate species (Weinstein 1983, Bucher 1992, Diamond 2002, Cronon 2009). The world as we know it is a direct result of our ability to name and catalog the natural world.

In 1735, Carl Linnaeus codified a binomial system of taxonomy, which has since become a cornerstone of Western biology and biodiversity science (Linnaeus 1735). While the primary function of Linnaean taxonomy is to document and organize knowledge of the living world, the names of species themselves take on additional functions, such as describing features of the organism (like where it is found or what it looks like), or honoring individuals. For example, in 2017, a new bird species was described from an outlying ridge of the Peruvian Andes. The bird was given the scientific name Myrmoderus eowilsoni in honor of the "Father of Biodiversity" - Edward O. Wilson (Moncrieff et al. 2018). In response, Wilson said that, "the idea of [having] a bird named after you is right up there with maybe the Nobel [Prize], because it's such a rarity to have a true new species discovered, and I do take it as a great personal honor" (Rainforest Trust 2017). As Wilson notes, descriptions of birds new to Western science have become rare events in the last 70 years (Figure $1 \mathrm{~A}$ ), and being the inspiration for a new species name is widely considered a great honor.

How a bird from the Peruvian Andes comes to be named after E.O. Wilson, a naturalist from the Southern U.S., can only be understood through a historical lens and by considering the societal interests and global structures put in place during centuries of European and U.S. imperialism (Richardson 2018). This history of European and U.S. conquest is inextricably tied to the enterprise of Western science. For example, critical advances in malaria research were funded and motivated by efforts in the late 19th century to curb European deaths in British colonies (Deb Roy 2013, 2018), and in 1902, Sir Ronald Ross received a Nobel Prize in Medicine for his work on the transmission of malaria, having argued that, "in the coming century, the success of imperialism will depend largely upon success with the microscope" (Science 1900). As historian Rohan Deb Roy writes, "[Ross'] point neatly summarised how the efforts of British scientists were intertwined with their country's attempt to conquer a quarter of the world" (Deb Roy 2018).

The reliance of Western science on imperial ventures (and vice versa) is probably best catalogued in the links between naturalists and slave trade, prospecting and resource extraction, and European exploration of the 18th and 19th centuries (Kean 2019, Wynn-Grant 2019). The impacts of these naturalists on present-day science are difficult to overstate; the voyages of naturalists like Charles Darwin on the Beagle and Sir Joseph Banks on the Endeavour were integral parts of an imperial enterprise (MacKenzie 1990, Carter 1995). 
74 Imperialism granted Western scientists unprecedented access to the world, which they

75 translated into scientific authority, power, and wealth, fueling narratives of white supremacy, while simultaneously disregarding (or appropriating) Indigenous knowledge. These narratives were used in turn to justify genocide, coercive labor, and exploitation, enabling the flow of material wealth and intellectual resources from colonized lands to metropoles (Galeano 1971, Said 1979). In settler colonial states, like the U.S., nation-building relied on European colonial and imperialist infrastructure for global access (e.g. Quintero Toro 2012). As a result, Western science is conducted through the same institutions and methods that thrived under and helped constitute European imperialism. Within this context, we can understand how species from formerly or currently colonized parts of the world (usually referred to as the "global South") come to be described by, and named after, scientists from former or current imperial metropoles, or the "global North".

In this study, we interrogate the ways in which imperialism and exclusion underlie modern scientific naming practices. We compile and analyze a dataset of species descriptions and their authors to ask: who has access and power to name species, and who is honored in species names? We focus our analysis on descriptions of birds because of their broad scientific and cultural relevance (e.g. Schuetz and Johnston 2019, Robinson 2019). We also limit our analysis to after 1950, when the opportunity to name new bird species becomes rare (Figure 1A), further intensifying the potential for recognition of authors and honorees with new descriptions. We find that global patterns of naming and authorship, extending into the present, are consistent with the historical exploitation of intellectual and material goods in the global South (Galeano 1971), and advance scientific authority in the global North, as expertise about the natural world continues to be disproportionately claimed by the global North. Our findings serve as a case study of the disparities that exist at the core of biological science. The implications of this study extend beyond inequity in naming practices and taxonomy, which is a facet of how biodiversity science is done in a global context. This study is a broader reflection on the inequitable structures that underlie Western scientific practices - inequities in access, labor, collaboration, power, and designations of expertise and authority. Our intention for this work is not to discredit the accomplishments of others, but rather provide context and promote conversations in our scientific communities that acknowledge and confront inequities in our practices.

\section{RESULTS}

Since 1950, 95\% of new bird species have been described from countries in the global South (n $=367$ of 385). During this period, only 17 species have been described from the global North (one species had an undetermined geographic placement). We classified countries and island regions as either global North or global South -here and throughout the study-based on the United Nations classifications for "developed" and "developing" regions

110 (https://unstats.un.org/unsd/methodology/m49/), with "developed" corresponding to the global 111 North, and "developing" corresponding to the global South (Rigg 2007). Since 1950, species 
112 have been described from 68 countries (Figure 2), but half of all species have been described

113 from five global South countries alone: Brazil $(n=68)$, Peru $(n=57)$, Colombia $(n=25)$,

114 Philippines $(n=23)$, and Indonesia $(n=20)$. Hereafter, we refer to the country where a species

115 was described from as its type locality.

116 Half of all species were named after people $(50 \%, n=193)$, like Myrmoderus eowilsoni. This 117 type of species name is known as an eponym. The other half of species were named after 118 defining characteristics $(50 \%, n=192)$, like morphological features, behavior, or where it is 119 found, like Pyrrhura peruviana. Over time the number of eponyms increases $\left(R^{2}=0.141, p=\right.$ $1200.001)$ as the other naming categories remain steady $\left(R^{2}=0.011, p=0.379\right.$; Figure $\left.1 B\right)$.

A

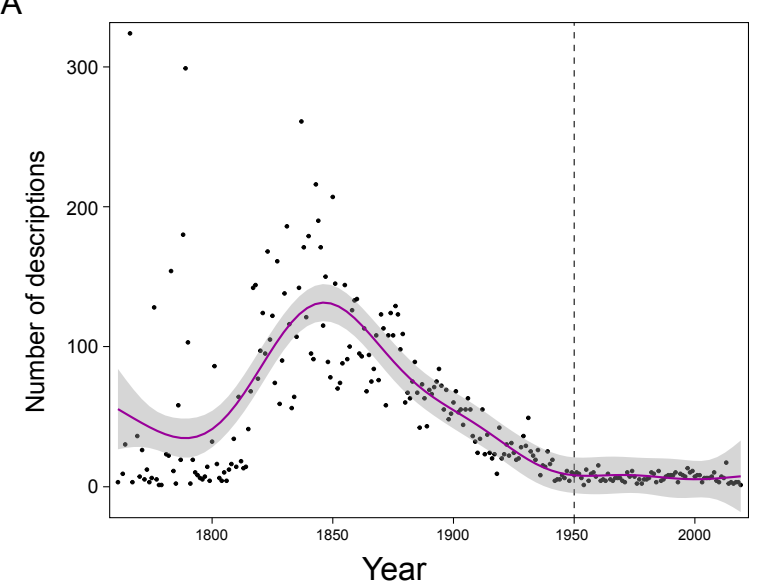

B

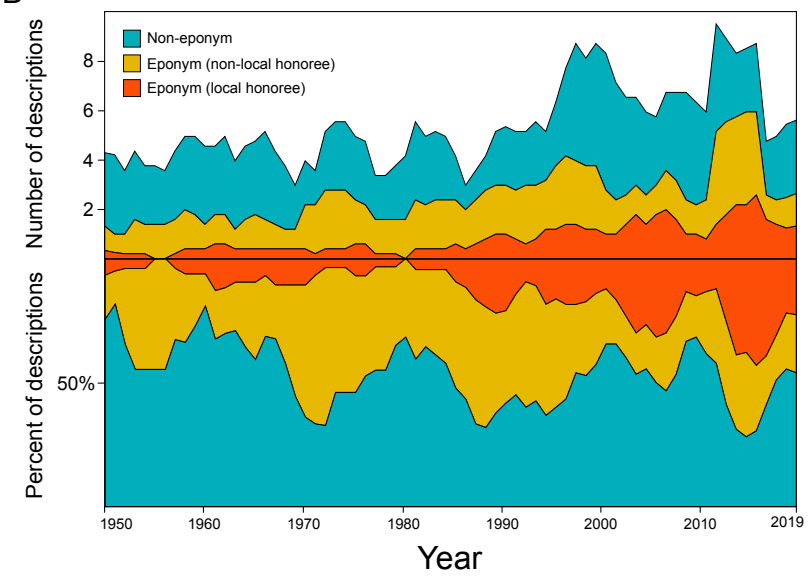

Figure 1. The number of bird species descriptions through time. (A) The number of descriptions by year that follow Linnaean taxonomy, starting after 1758, when Carl Linnaeus initially described 554 birds in the 10th edition of Systema Naturae (Linnaeus 1758). The purple line is a LOESS regression with $95 \%$ confidence intervals (shaded gray area). The dotted vertical line marks the point in time at which the dataset for this study begins, once the magnitude of species descriptions bottoms out in the mid-twentieth century. (B) The total number (top) and percent (bottom) of descriptions split by naming category from 1950 to present, plotted as a five-year moving average. Species names that honor individuals (eponyms) are divided into two categories: eponyms that honor individuals from the country where the bird was described (local honoree), and eponyms that honor individuals from somewhere other than the country where the bird was described (non-local honoree). We binned all species names that are not eponyms (e.g. morphonyms, toponyms, etc.) into the third grouping (Non-eponym). 


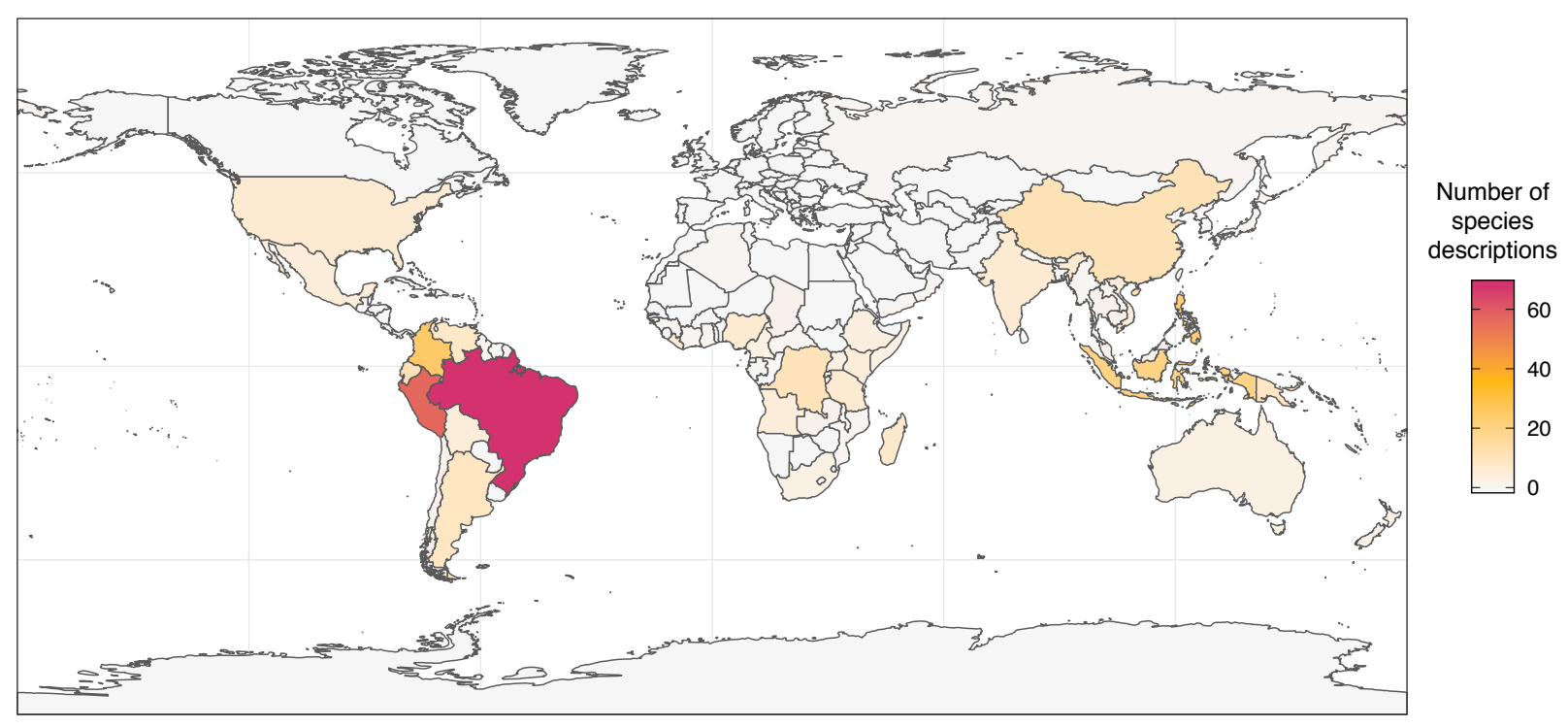

Figure 2. The number of bird species described from a given country from 1950 to 2019.

\section{Who has access and power to name species?}

Over the last 70 years, 545 individuals authored 385 species descriptions, filling a total of 1012 author positions (descriptions have anywhere from 1 to 16 authors). We compiled data on where each author was from to infer where an author received their formative education (hereafter, referred to as their country of origin). Using publicly available sources, we inferred an author's country of origin from a combination of where they were born and where they received an undergraduate education (details of this method are discussed in the Methods). We were able to compile data for $76 \%$ of all authors $(n=412$ of 545$)$ and for $84 \%$ of total author positions $(n=848$ of 1012). Of these authors, $62 \%(n=255)$ are from the global North and $38 \%(n=157)$ are from the global South. We also recorded the institutional affiliation (at the time of the species description) for $98 \%$ of total author positions, which shows a similar pattern: $60 \%$ of authors were affiliated with institutions in the global North $(n=595)$, and $40 \%$ were affiliated with institutions in the global South $(n=393)$. These results show that the majority of authors are from the global North and affiliated with global North institutions.

When we consider that $24 \%$ ( $n=133$ of 545 ) of authors have missing country of origin data in our dataset, our results likely underestimate the percentage of authors from the global North, which suggests that the geographic skew in authorship is more extreme. This dynamic can be understood when we assess individuals in the dataset with known birthplace and institutional affiliations (which accounts for $59 \%$ of authors): $72 \%(n=236)$ of authors were born in the same country as the institutions where they worked, and $7 \%(n=23)$ of authors were born in the same country as at least one of the institutions where they worked (i.e. these 23 authors were 143 affiliated with multiple institutions in different countries). Of the remaining $21 \%$ of authors $(n=$ 
144 67) who were born in a country that was different from the institutions where they worked, this 145 movement was largely within the global North $(33 \%, \mathrm{n}=22)$ or from the global North to global 146 South institutions $(49 \%, n=33)$. We documented one instance of movement within the global 147 South, and only $16 \%$ of authors $(n=11)$ who shifted countries moved from the global South to 148 global North institutions. Given the much higher prevalence of movement within the global North 149 and from the global North to global South institutions, these data suggest that the percent of 150 authors whose country of origin is in the global North should be higher than the percent of 151 authors whose institutional affiliation (for which our dataset is $98 \%$ complete) is in the global 152 North.

First authors, author lists, and authority

154 In the biological sciences, the first author on a publication typically receives the most credit for 155 the work, and this author is viewed as a primary authority on a publication's contents 156 (Tscharntke et al. 2007, Shen and Barabási 2014). We therefore examined metrics for first authors to explore who is perceived by the scientific community as the authority on a species description. We found that $71 \%$ of first authors $(n=275)$ are from the global North, and $21 \%(n$ $=82)$ are from the global South. The country of origin for $7 \%$ of first authors $(n=28)$ was unknown. In $55 \%$ of the cases where the first author is from the global South $(n=45)$, all authors on the description are from the global South. The first author's country of origin was different from the species' type locality for $72 \%$ of species descriptions $(n=276)$, and the same for $22 \%$ of species descriptions $(n=85)$. The first author's country of origin was unknown for the remaining $6 \%$ of descriptions $(n=24)$ (for one description the species' type locality was unknown). The prevalence of first authors from the global South increases significantly toward the present $\left(R^{2}=0.143, p=0.014\right)$, but the prevalence of first authors from the global North remains consistent $\left(R^{2}=6.749 e-5, p=0.947\right)$ and is always higher (Figure $3 A$ ).

When we looked at institutional affiliation, $70 \%$ of first authors $(n=268)$ were affiliated with institutions in the global North, $27 \%$ of first authors $(n=104)$ were affiliated with institutions in the global South, and the institutional affiliation was unknown for $3 \%$ of first authors $(n=13)$. Similar to the authors' country of origin patterns, the prevalence of first authors from global South institutions increases significantly toward the present $\left(R^{2}=0.142, p=0.007\right)$, but the prevalence of first authors from global North institutions remains consistent $\left(R^{2}=0.018, p=\right.$ 0.282) and is always higher (Figure 3B). Taken together, these data show that the perceived authorities on species described from the global South are largely scientists from the global North.

We found an increase (though non-significant) through time in the percent of species descriptions for which the first author's country of origin is the same as the species' type locality $\left(R^{2}=0.053, p=0.137\right.$; Figure $\left.3 C\right)$. However, for most descriptions, the first author's country of origin was different from the species' type locality (Figure 3C,E). In fact, for $51 \%$ of descriptions ( $n=195)$, not a single author was from the species' type locality. For $39 \%(n=149)$ of 
A

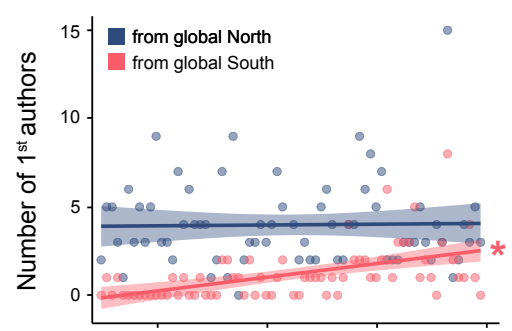

B

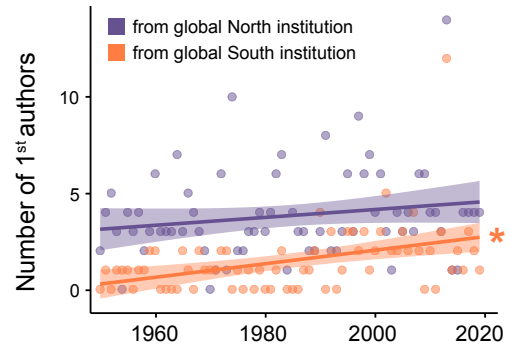

C

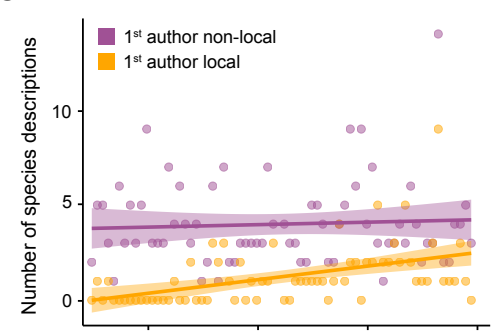

$\mathrm{D}$

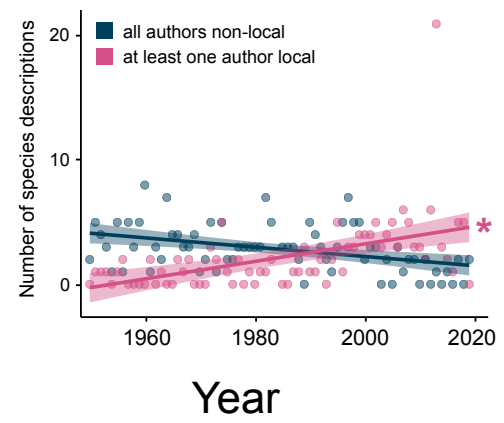

$\mathrm{E}$

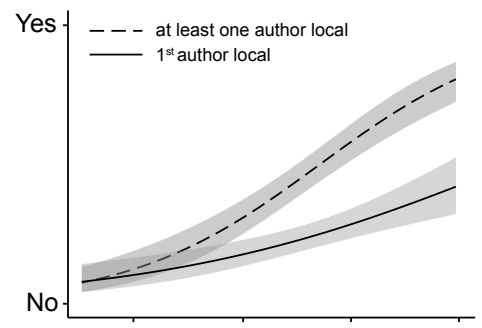

$\mathrm{F}$

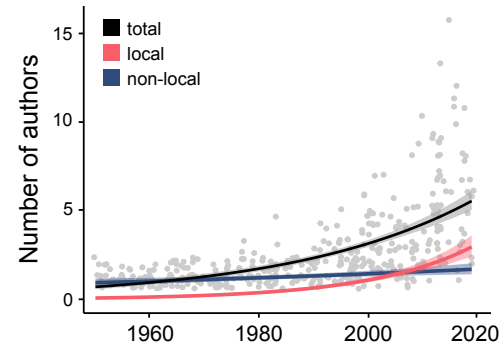

Figure 3. Authors' country of origin and institutional affiliation through time. (A) The number of first authors for a given year whose country of origin is in the global North vs. global South. (B) The number of first authors for a given year whose institutional affiliation is in the global North vs. global South. (C) The number of species descriptions for a given year in which the first author's country of origin is the same as the species' type locality (1st author local) or different (1st author non-local). (D) The number of species descriptions for a given year in which at least one author is from the species' type locality (at least one author local) vs. when not a single author is from the species' type locality (all authors nonlocal). In panels $A-D,\left(^{*}\right)$ denote significant changes $(p<0.05)$ in the response variable through time from simple linear models. Each point is the number of descriptions in a given year for each category. (E) Logistic regressions of the data from panels $C$ (solid line) and D (dotted line), showing changes through time in whether or not species descriptions have local first authors or at least one local author. (F) The total number of authors on a description (total), and the number of authors on a description in which an authors' country of origin is the same (local) or different (non-local) from the species' type locality. Lines plot Poisson regressions. Each gray point is the number of authors on each species description. For all panels, shaded areas are 95\% confidence intervals for each regression.

descriptions at least one author was from the species' type locality, and this information was unknown for the remaining $11 \%$ of descriptions $(n=41)$. Toward the present, however, we

184 found a significant increase in descriptions that include at least one author from the species' type locality $\left(R^{2}=0.189, p=0.002\right)$, and a near-significant decrease in descriptions without a single author from the species' type locality $\left(R^{2}=0.056, p=0.068\right.$; Figure $\left.3 D\right)$, resulting in a pattern inversion in the 1990s (Figure 3E). That is, before 1990, most author lists were exclusively non-local, while after 1990, most author lists included at least one author from the 189 species' type locality (Figure 3D,E). 
When we look at the entire author list for a species description, the number of authors increases significantly toward the present (GLM: $X^{2}=292.54, p<0.001$; Figure 3F), which appears to be driven by the addition of authors from the global South (Figure 3F), rather than changes in the number of authors from the global North, which remains relatively stable through time (Figure $3 F)$. This result reflects a significant increase toward the present in the percent of authors whose country of origin matches the species' type locality (GLM: $X^{2}=187.96, p<0.001$; Figure 3F).

We found that $85 \%$ of species descriptions are published in journals based in the global North $(n=329) ; 13 \%$ of descriptions are published in journals based in the global South $(n=51)$, and five descriptions are published in journals with unknown geographic placement. We also determined the language of each description based on its title. We found that $70 \%$ of descriptions are published in journals that are based in countries where English is recognized as an official language $(n=268)$, but $82 \%$ of descriptions are written in English $(n=316)$. This excess of English-language descriptions consists of 57 descriptions written in English that are published in journals based in countries where English is not an official language. The other languages of species descriptions are: Portuguese $(n=20)$, French $(n=18)$, German $(n=14)$, Spanish $(n=9)$, Russian $(n=1)$, and Vietnamese $(n=1)$. We were unable to classify language for six species descriptions.

210 Of the species named after a single person $(n=183)$, the type locality for $96 \%$ of these species are in the global South, but the majority of these eponyms are named in honor of individuals from the global North: $68 \%(n=124)$ of eponyms honor individuals from the global North, while $30 \%(n=54)$ honor individuals from the global South. The honoree's country of origin was unknown for 5 eponyms. Looking at the countries from where each bird was described, only $31 \%(n=56)$ of eponyms honor individuals from the species' type locality, while $67 \%(n=122)$ of eponyms honor individuals from a different country. Additional eponyms are named after fictional characters, honorific titles, or have unknown etymology $(n=7)$, or are named after groups of people $(n=8)$, of which three are named after indigenous groups from the region where the species occurs. Although the majority of eponyms honor individuals from the global North, we found an increase toward the present in eponyms that honor local individuals - i.e. from the global South $\left(R^{2}=0.242, p<0.001\right.$; Figure $\left.1 B\right)$.

When the first author's country of origin is consistent with the species' type locality, the species is $62 \%$ more likely to be named in honor of someone from that country (GLM: $X^{2}=18.68, p<$ 0.001 ; Figure 4). Regardless of first authorship, however, if there is at least one author whose 
country of origin matches the species' type locality, then the species is $47 \%$ more likely to be named in honor of someone from that country (GLM: $X^{2}=21.88, p<0.001$; Figure 4).

\section{Gender disparity in eponyms}

Based on the Latin endings of species names, we also assessed gender designations for individuals honored in eponyms $(-\mathrm{ae}=$ woman, $-\mathrm{i}=$ man, - orum $=$ group of women $/ \mathrm{men}$ or group of all men, -arum = group of women). The Latin language and the codes that manage Linnaean taxonomy impose binary gender designations for eponym names (ICZN Article 31.1.2 [animals], ICNafp Article 60.8 [plants], ICNB Appendix 9 [bacteria]). This practice reflects gendered rules and language that have governed Linnaean taxonomy for almost three centuries, and consequently erase the identities of nonbinary individuals, while also imposing gender identities. Of the eponyms that are named after a single individual $(n=183), 81 \%(n=149)$ honor men, and $19 \%(n=34)$ honor women. The observed gender disparity in eponyms is also paired with disparities in how authors characterize honorees within the text of species descriptions. For example, men who are honored are often described as colleagues and friends, notable scientists, and patrons, while half of all eponyms that honor women describe these women as wives $(n=13)$ and daughters $(n=4)$. To put these differences into perspective, only one male honoree is characterized as a son, and not a single male honoree is characterized as a husband. The observed gender disparity in who is honored as a source of knowledge is itself a manifestation of the epistemic sexism/racism that defines Western science as a colonial and imperial project (Grosfoguel 2013). This disparity is further reflected in the fact that $59 \%(n=20)$ of eponyms that honor women use only their given name, while $12 \%(n=4)$ use given name and surname, and $29 \%(n=10)$ use only surname. In contrast, only $1 \%(n=2)$ of eponyms that honor men use only their given name, while $2 \%(n=3)$ use given name and surname, and $97 \%$ $(n=144)$ use only surname.

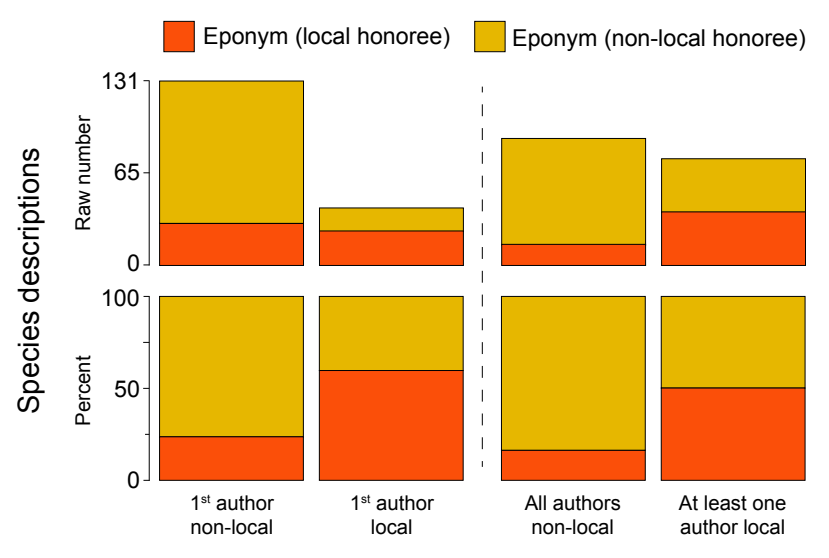

Figure 4. Eponym patterns based on an author's country of origin, comparing eponyms that honor individuals from the country where the bird was described (local honoree), and eponyms that honor individuals from somewhere other than the country where the bird was described (non-local honoree). The four author classifications follow the classifications in Figure 3B,E. The top plots show the raw number of species descriptions in each category. The bottom plots show the percent of species descriptions in that category. 
Our results show how foundational practices in Western science still adhere to global structures of access and power that disproportionately benefit the global North. As professional scientists from the global North who are affiliated with global North institutions, we (the authors) have had access to funding and career opportunities in science that are the product of the wealth amassed through a history of genocide, coercive labor, land seizure, and resource extraction by the U.S. and Britain (e.g. see Jordan at al. 2018; please see our statement of Land Acknowledgement below). We recognize that our affiliations with global North institutions have provided us with largely unrestricted access to work in the global South. As our findings highlight, this access to the global South continues to be translated into scientific authority, power, and material wealth (e.g. in the form of careers) in the global North. While we can understand this dynamic by examining the global structures of access and power put in place during centuries of European and U.S. imperialism, a historical perspective alone ignores the agency of institutions and scientists in present-day actions. By ignoring the inequities embedded in Western science, we re-enact and uphold structures of domination and imperialism in our research practices.

\section{Inclusion, access, and power within Western science}

The patterns of authorship we observed show that researchers from the global South have increasing access to Western science (Figure 3), which appears to impact naming outcomes (see Figure 4). We see an increase through time in the number of authors on a description, which is driven almost exclusively by an increase in authors from the global South (Figure 3F). This formal inclusion of global South authors, however, does not broadly translate into Western metrics of primary authority, like first authorship (compare the differences between Figure $3 \mathrm{C}$ and D). As a result, Western scientific authority continues to be consolidated in the global North. The increase in global South authors tracks the efforts in recent years by global North institutions to expand participation in Western science (Mervis 2016, Valantine et al. 2016), and also tracks the recent increase in international collaborations (Coccia and Bozeman 2016). These two academic trends have been motivated by a model in which diversity and inclusion equal better science, higher rankings, and increased marketability (Iwasaki 2019, Henderson and Herring 2013, Berrey 2011). These initiatives, however, are documented to be largely symbolic, utilizing labor and collaborations to serve academic markets in the global North and legitimize authority and dominance structures already in place (Ahmed 2017, Khan et al. 2019, Henry et al. 2017). This model of inclusion and collaboration prioritizes the global North's power to theorize and conceptualize (e.g. the scientist that extrapolates the observation of an individual bird to the naming of a full species), while relying on the global South to connect the work to the material world (e.g. the local guide/resident/scientist who facilitates the physical work to find the individual bird) (Alvarez and Coolsaet 2020). Furthermore, this model of inclusion frames the value of people and their perspectives in terms of how they can benefit those currently in power, without challenging those power structures (e.g. Johnson 2020). 
An example that illustrates how Western science allows inclusion insofar as power structures are maintained is the expectation of professional English as its language. English is the linguistic currency of Western science, placing the burden of inclusion on the person seeking inclusion, e.g. a non-native English speaker from the global South. This expectation of English is highlighted in our dataset, for example, in the higher percentage of descriptions written in English (82\%) than the percentage of descriptions published in journals based in Englishspeaking countries (70\%). Getting to the point where a non-native English speaker can write a species description assumes not only that the researcher has something to write about (e.g. a bird), but that the researcher has had access to English classes and/or English-speaking colleagues/contacts/editing services, by way of financial means, time, a global social network, or institutional support. In contrast, scientists from English-speaking countries already know the language of Western science.

It is essential to acknowledge that this study looks at knowledge production, access, and power within Western naming practices from the perspective of the global North. Implicit in this perspective is that first authorship, and authorship of publications in general, are ways to establish authority and accumulate power in knowledge production, which in itself is worth questioning. For example, how do established authorship norms promote inequity and dominance in Western science (e.g. Pender and Shaw 2020, Ward-Fear et al. 2020)? Furthermore, while our work examines dynamics between the global North and South within a Western context, these dynamics are mirrored in broader structures of dominance between Western science and Indigenous science (as defined by Ogawa 1995). The imperial dynamics that created the current structures of access and power within Western science between the global North and South have also enabled Western science to assert dominance in global knowledge production (de Sousa Santos 2018, Manathunga 2020), while erasing, appropriating, and subjugating Indigenous knowledge and authority. Solutions to build a more equitable global scientific community -if that is in fact our goal within Western institutions- will ultimately require actions that redress current structures of dominance and authority built on a history of dispossession, violence, and white supremacy.

\section{The consequences of upholding imperial structures of power and authority}

The observed disparities in eponyms and authorship raise ethical and practical questions about how science is done in a global context. For example, what does it mean for power and authority over the natural world to be disproportionately claimed by the global North (Meneghini et al. 2008, Mori et al. 2015, Espin et al. 2017)? What are the consequences for a community's relationship to the environment when scientific authority over that environment is held/claimed by individuals outside of the local community (Mammides et al. 2016, de Vos 2020)? What does it mean for work in the global South to be translated and consolidated into authority, prestige, and careers in the global North? Our intention here is not to prescribe particular answers to the above questions because the formulations of those answers will require dialogue between the 
hegemonic communities in which we are embedded and those excluded and marginalized by them. Rather, our goal for this paper is to promote conversations and actions around these questions, and contribute to the work already being done within and outside the academy that re-frames approaches to science to confront inequity in present-day practices (for examples of recent work see Maile 2015 and https://decolonize-dna.org), while acknowledging our collective agency in these practices (Perrotta and Alonso 2020). As an entry point for these conversations, we recommend working through the questions in the Research Justice Worksheet found at:

We have found this resource helpful for personal reflection and group discussion (thanks, Supriya). We recognize that these questions may be uncomfortable and even painful for some (as they have been for us). We invite and challenge you to work through this discomfort.

Linnaean taxonomy reflects a social history and practice that continues to consolidate authority in the global North under the guise of scientific objectivity. As we grapple with the questions above as a global community, Western science must give up the fallacy of presenting itself as neutral and objective (Latour and Woolgar 1979, Proctor 1991, Harding 1992, Sheth 2019, Alves 2020), which remains a dominant tenet of training and discourse to this day. As sociologist William Jamal Richardson reminds us, "[we] can't understand the production of knowledge and science independent of its relationship to societal interests and structures of power" (Frickel and Moore 2015, Richardson 2018). Adhering to the fallacy of neutrality (which is in fact a non-neutral stance and one embedded in white supremacy; Grosfoguel 2013, Prescod-Weinstein 2015, Saini 2019) has allowed scientists to ignore the social impacts of our actions past and present, while upholding global and institutional structures of dominance and inequity, regardless of intent.

\section{METHODS}

\section{$351 \quad$ Dataset}

As our base dataset, we used the Birdlife International global avian checklist, which is regarded as a dominant authority in avian taxonomy (HBW and BirdLife Taxonomic Checklist v4 Dec 2019). Importantly, this checklist includes information on the authors and year of each species' description. For entries from 1950 to present, we removed taxa that are currently recognized as species but were originally described as subspecies. We identified these entries by looking at the original species/subspecies description for each entry. Removing these taxa ensures that the level of honor at which a taxon is described is consistent between entries. Additionally, we added in taxa for which the opposite scenario is true - that is, we included taxa that were originally described as species following Linnaean taxonomy but are not currently recognized as species by the BirdLife International checklist committee. We included these "invalid" species in 
the dataset because they were originally described with the intention of being at the species level. We identified these taxa using Bird Species New to Science: Fifty Years of Avian Discoveries (Brewer 2018), which reports a comprehensive list of taxa described as species between 1960 and 2015. For taxa described as species between 2015 and 2019, we conducted a literature search to identify recently described species to include in the dataset. Lastly, we did not include descriptions in which the species was extinct at the time of description. Figure $1 \mathrm{~A}$ includes all (and only) entries from the HBW and BirdLife Taxonomic Checklist v4, but for all subsequent figures and analyses, subspecies and extinct taxa were removed, and "invalid" 370 species were included.

\section{Type localities, species name categories, and etymology of eponyms}

We defined a species' type locality as the country from where the species was described, which we determined from locality data associated with holotype specimens.

We classified species names based on their meaning and derivation, placing each species into one of nine naming categories defined in the Helm Dictionary of Scientific Bird Names (Jobling 2010). The categories include: (1) eponym - named after a person or persons; (2) morphonym - named after morphological characteristics, like plumage; (3) toponym - named in reference to a geographic place; (4) autochthonym - named in an indigenous language; (5) taxonym named in relation to other taxa; (6) bionym - named after habitat or environmental conditions; (7) ergonym - named after behavioral characteristics, like breeding or display behaviors; (8) phagonym - named after diet or prey type; and (9) phononym - named after vocal characteristics.

We further divided eponyms into five categories: (1) local - named after an individual from the species' type locality; (2) non-local - named after an individual from a country other than the species' type locality; (3) fictional - named after a fictional character; (4) titles - named after an honorific title, like Prince; and (5) group - named after a group of people. To determine if an eponym was local or non-local, we had to first infer where an honoree was from, which we defined as the country where they were born, and determined using The Eponym Dictionary of Birds (Beolens et al. 2014). For example, the entry for Maria Koepcke says, "born Maria Emilia Ana von Milkulicz-Radecki in Leipzig, Germany," and the entry for Alfonso Maria Olalla says, "an Ecuadorian professional collector, who lived in Brazil (mid-1930s) and took Brazilian citizenship." We recorded the countries where they were from as Germany and Ecuador, respectively. For individuals who lack this information in The Eponym Dictionary of Birds, we determined where they were born from other publicly available sources, such as curriculum vitae available online or In Memorias published in society journals. 


\section{Author metrics}

397 We compiled author data from the publication of each species description. We recorded the 398 number of authors on each publication and each author's institutional affiliation. For authors with 399 more than one affiliation listed, we used their first institution listed for our analyses, as this 400 institution is given and perceived as having priority. When an author's institutional affiliation was 401 not included in a species description, which is the case for some publications earlier in the 402 dataset, we inferred their institutional affiliation at the time of publication (when possible) from 403 other publicly available sources, such as In Memorias.

404 We inferred an author's country of origin based on where they were born or where they received 405 an undergraduate education, which we compiled from publicly available sources, such as In 406 Memorias, personal websites, curriculum vitae, etc. Our country of origin metric is intended to 407 capture: (1) the place where an individual received their formative education, and (2) the 408 academic conventions under which they were trained. We defined an author's country of origin 409 as the country where they were born (61\% of authors), but when this information was 410 unavailable, we used the country of their undergraduate institution when available (14\% of 411 authors). This combined approach helps us increase coverage, and when both data types were 412 available for an author (34\% of authors), the two metrics show $93 \%$ congruence.

\section{Statistical analysis}

414 We assess changes in authorship patterns through time using simple linear regressions (Figure 415 1B and Figure 2A-D), logistic regressions (Figure 2E), and Poisson regressions (Figure 2F), 416 with year as a single predictor variable. We analyzed if eponym patterns (local honoree vs. non417 local honoree) were significantly predicted by the authors' country of origin (local vs. non-local) 418 using logistic regressions, with year as a fixed effect (Figure 3). All analyses were conducted in 419 R v3.6.2 (R Core Team 2013). 


\section{LAND ACKNOWLEDGEMENT}

421 Our ability to write this paper is made possible through institutional access and support enabled 422 by coercion and theft, and ongoing occupation of indigenous land. In particular, the University of 423 Michigan and the University of Chicago/Field Museum are situated on the lands of the Council 424 of the Three Fires - comprised of the Ojibwe, Odawa, and Potawatomi Nations - as well as the 425 Miami, Ho-Chunk, Menominee, Sac, Fox, Kickapoo, and Illinois Nations. For this reason, we are 426 complicit in the ongoing oppression of peoples indigenous to and displaced from these 427 territories. Along with the seizure of lands, our institutions and practices have contributed to the 428 erasure and oppression of indigenous sovereignty and knowledge. We call for our community 429 to: (1) reflect on the objectives and impacts of our science, (2) acknowledge and respect 430 indigenous autonomy and self-determination, and (3) recognize that our objectives are not 431 justification for the violation of indigenous autonomy and self-determination.

\section{ACKNOWLEDGEMENTS}

433 We thank Alvita Akiboh, Alejandra Anchante, Giorgia Auteri, John Bates, Carlos Daniel Cadena, 434 Susanna Campbell, Claudio Gómez-Gonzáles, Eric Gulson-Castillo, Constanza de la Fuente 435 Castro, Michael Lyons, Bruce O'Brien, Diana Macias, Teresa Pegan, Thomas Stewart, K. 436 Supriya, Armando Valdés-Velásquez, Kristen Wacker, Z Yan Wang, Brian Weeks, Ben Winger, 437 Christopher Witt, and Marketa Zimova for their discussions and feedback on the manuscript.

\section{LINK TO SUPPLEMENT}

439 Versión del manuscrito en español (Spanish language version of manuscript)

440 https://drive.google.com/file/d/1iloVAaqUznEOoWqejXfFclGtf9-TnbUt/view?usp=sharing 


\section{DEFINITIONS BOX: Definitions of terms, and how we use terms in the text.}

country of origin - The country where an author was born and/or where they received an undergraduate education. This metric is intended to capture where an individual received their formative education, and the academic conventions under which they were trained.

eponym - a name (in this case, the scientific name of organisms) that "commemorates a real person or a mythological or fictional character" (Jobling 2010).

global North/global South - We classified countries and island regions as either global North or global South based on the United Nations classifications for "developed" and "developing" regions with "developed" corresponding to global North and "developing" corresponding to the global South. These terms are not strict geographical categorizations of the world but "based on economic inequalities which happens to have some cartographic continuity" (Rigg 2007). Countries such as Australia and New Zealand, for example, are considered as part of the global North. The North/South designations are associated with the Brandt report (1980) which argued that North/South is broadly synonymous with rich/poor and developed/developing, "although neither is a uniform or permanent grouping" (Brandt 1980).

imperialism - The ideology and practice of domination over the territories of sovereign peoples. "By the late nineteenth century, imperialism [was] used to describe the development or maintenance of power ("hegemony") of one country over another through economic, diplomatic, and cultural domination even in the absence of direct colonial occupation" (Young 2015).

Indigenous science - The science of a local culture and society (Ogawa 1995). In contrast to Western science (which is rooted in European culture), Indigenous science is not rooted in one cultural background. We do not use the term Indigenous science to imply a shared ontology or history among indigenous cultures, but rather, to refer to the concept of science and knowledge production that is rooted in local culture and society.

metropole - The central territory of a colonial state (i.e. the colonizing sovereign state). For example, the U.S. is the metropole of Puerto Rico and Guam. Great Britain, Spain, and Portugal are the former metropoles for much of the Americas.

(settler) colonialism - “...a specific mode of domination where a community of exogenous settlers permanently displace to a new locale, eliminate or displace indigenous populations and sovereignties, and constitute an autonomous political body." (Veracini 2010). While our study focuses primarily on imperial dynamics, imperialism and colonialism are closely tied.

type locality - The country where a species is described from.

Western science - A system of knowledge-production that rose to prominence in the 17th and 18th centuries as part of European empire building, and is currently a dominant form of knowledge production globally (Medin and Bang 2014). Western science is rooted in ancient Greek philosophy and science, although its foundations are heavily influenced by a broader range of intellectual traditions - such as those in central Asia, as well as Babylonian and Islamic science (Lindberg 2007, Ragep 2009). 


\section{REFERENCES}

442 Ahmed, S. (2017). Living a Feminist Life. Duke University Press.

443 Álvarez, L. \& Coolsaet, B. (2020). Decolonizing Environmental Justice Studies: A Latin

444 American Perspective. Capitalism Nature Socialism 31(2), 50-69.

445 Alves, M. (2020). The Natural Fallacy in a Post-Truth era: A perspective on the natural sciences' 446 permeability to values. EMBO reports, 21(2), e49859.

447 Atran, S. (1998). Folk biology and the anthropology of science: Cognitive universals and cultural 448 particulars. Behavioral and brain sciences, 21(4), 547-569.

449 Beolens, B., Watkins, M., \& Grayson, M. (2020). The eponym dictionary of birds. Bloomsbury 450 Publishing.

Berlin, B. (2014). Ethnobiological classification: Principles of categorization of plants and animals in traditional societies. Princeton University Press.

453 Berrey, E. C. (2011). Why diversity became orthodox in higher education and how it changed 454 the meaning of race on campus. Critical Sociology 37(5), 573-596.

455 Brewer, D. (2018). Birds New to Science: Fifty Years of Avian Discoveries. Bloomsbury 456 Publishing.

457 Brown, C. H. (1984). Language and living things: Uniformities in folk classification and naming. 458 Rutgers University Press.

459 Brown, W. (2005). Edgework: Critical Essays on Knowledge and Politics. Princeton University 460 Press.

461 Bucher, E. H. (1992). The causes of extinction of the passenger pigeon. In Current ornithology 462 (pp. 1-36). Springer, Boston, MA.

463 Carter, H. B. (1995). The Royal Society and the voyage of HMS Endeavour 1768-71. Notes and 464 Records of the Royal Society of London, 49(2), 245-260.

465 Corbera, E., Calvet-Mir, L., Hughes, H., \& Paterson, M. (2016). Patterns of authorship in the 466 IPCC Working Group III report. Nature Climate Change, 6(1), 94-99.

467 Coccia, M. \& Bozeman, B. (2016). Allometric models to measure and analyze the evolution of 468 international research collaboration. Scientometrics 108, 1065-1084. 
Darwin, C. (1859). On the origin of species by means of natural selection, or, the preservation of favoured races in the struggle for life. London: J. Murray.

472 de Sousa Santos, B. (2018). The end of the cognitive empire: The coming of age of 473 epistemologies of the South. Duke University Press.

474 de Vos, A. (2020). The Problem of 'Colonial Science'. Scientific American. Available at 475 https://www.scientificamerican.com/article/the-problem-of-colonial-science/

476 Deb Roy, R. (2013). Quinine, mosquitoes and empire: reassembling malaria in British India, 477 1890-1910. South Asian history and culture, 4(1), 65-86.

478 Deb Roy, R. (2018). Decolonise science - time to end another imperial era. The Conversation. 479 Available at https://theconversation.com/decolonise-science-time-to-end-another-imperial-era$480 \quad 89189$

481 Diamond, J. (2002). Evolution, consequences and future of plant and animal domestication. 482 Nature, 418(6898), 700-707.

483 Espin, J., Palmas, S., Carrasco-Rueda, F., Riemer, K., Allen, P.E., Berkebile, N., Hecht, K.A., 484 Kastner-Wilcox, K., Núñez-Regueiro, M.M., Prince, C. and Rios, C. (2017). A persistent lack of 485 international representation on editorial boards in environmental biology. PLoS biology, 15(12), 486 p.e2002760.

487 Frickel, S., \& Moore, K. (Eds.). (2006). The new political sociology of science: Institutions, 488 networks, and power. Univ of Wisconsin Press.

489 Galeano, E. (1971). Las Venas Abiertas de América Latina. siglo xxi editores, s. a. de c. v.

490 Grosfoguel, R. (2013). The Structures of Knowledge in Westernized Universities: Epistemic 491 Racism/Sexism and the Four Genocides/Epistemicides of the Long 16th Century. Human 492 Architecture: Journal of the Sociology of Self-Knowledge 11(1): 8. Available at 493 http://scholarworks.umb.edu/humanarchitecture/vol11/iss1/8

494 Harding, S. (1992). After the neutrality ideal: Science, politics, and" strong objectivity". Social 495 research, 567-587.

496 HBW and BirdLife International (2019) Handbook of the Birds of the World and BirdLife 497 International digital checklist of the birds of the world. Version 4. Available at 
http://datazone.birdlife.org/userfiles/file/Species/Taxonomy/HBWBirdLife_Checklist_v4_Dec19.zip

500 Henderson, L. \& Herring, C. (2013). Does critical diversity pay in higher education? Race, gender, and departmental rankings. Politics, Groups, and Identities 1(3): 299-310. racialization, and indigeneity in Canadian universities. Race, Ethnicity and Education 20(3), 300314.

Iwasaki, A. (2019). Why we need to increase diversity in the immunology research community. Nature Immunology 20, 1085-1088.

507 Jobling, J. A. (2010). Helm dictionary of scientific bird names. A\&C Black.

508 Jordan, C., Mount, G. E., \& Parker, K. P. (2018). "A disgrace to all slave-holders": The 509 University of Chicago's Founding Ties to Slavery and the Path to Reparations. The Journal of 510 African American History, 103(12), 163-178.

511 Kean, S. (2019). Historians expose early scientists' debt to the slave trade. Science. Available 512 at https://www.sciencemag.org/news/2019/04/historians-expose-early-scientists-debt-slave513 trade

514 Khan, M. S., Lakha, F., Tan, M. M. J., Singh, S. R., Quek, R. Y. C., Han. E., Tan, S. M., 515 Haldane, V., Gea-Sánchez, M., LegidoQuigley, H. (2019). More talk than action: Gender and 516 ethnic diversity in leading public health universities. The Lancet 393(10171), 594-600.

517 Latour, B., \& Woolgar, S. (1979). Laboratory life: The construction of scientific facts. Princeton 518 University Press.

519 Lindberg, D. C. (2007). The beginnings of Western science: The European scientific tradition in 520 philosophical, religious, and institutional context, prehistory to AD 1450. University of Chicago 521 Press. Second edition.

522 Linnaeus, C. (1735). Systema naturae, sive regna tria naturae systematice proposita per 523 classes, ordines, genera, \& species. Lugduni Batavorum.

524 Linnaeus, C. (1758). Systema naturae per regna tria naturae :secundum classes, ordines, 525 genera, species, cum characteribus, differentiis, synonymis, locis (10th ed.). Laurentii Salvii: 526 Stockholm.

527 MacKenzie, J. M. (Ed.). (1990). Imperialism and the natural world. Manchester University Press. 
Mace, G. M., \& Lande, R. (1991). Assessing extinction threats: toward a reevaluation of IUCN threatened species categories. Conservation biology, 5(2), 148-157.

530 Maile, D. (2015). Science, Time, and Mauna a Wākea: The Thirty-Meter Telescope's CapitalistColonialist Violence. The Red Nation. Available at https://therednation.org/2015/05/13/sciencetime-and-mauna-a-wakea-the-thirty-meter-telescopes-capitalist-colonialist-violence-an-essay-intwo-parts/

Mammides, C., Goodale, U.M., Corlett, R.T., Chen, J., Bawa, K.S., Hariya, H., Jarrad, F., international conservation literature: A stalled process?. Biological Conservation, 198, pp.78-83.

537 Manathunga, C. (2020). Decolonising higher education: creating space for Southern sociologies of emergence. SOTL in the South 4(1): 4-25.

539 Medin, D. L., \& Bang, M. (2014). Who's asking?: Native science, western science, and science education. MIT Press.

541 Meneghini, R., Packer, A. L., \& Nassi-Calo, L. (2008). Articles by Latin American authors in 542 prestigious journals have fewer citations. PLoS One, 3(11), e3804.

543 Mervis, J. (2016). NSF makes new bid to boost diversity. Science 351, 6277.

544 Moncrieff, A. E., Johnson, O., Lane, D. F., Beck, J. R., Angulo, F., \& Fagan, J. (2018). A new 545 species of antbird (Passeriformes: Thamnophilidae) from the Cordillera Azul, San Martín, Peru. 546 The Auk: Ornithological Advances, 135(1), 114-126.

547 Mori, A. S., Qian, S., \& Tatsumi, S. (2015). Academic inequality through the lens of community 548 ecology: a meta-analysis. PeerJ, 3, e1457.

549 Myers, N., Mittermeier, R. A., Mittermeier, C. G., Da Fonseca, G. A., \& Kent, J. (2000).

550 Biodiversity hotspots for conservation priorities. Nature, 403(6772), 853.

551 Perrota, D. \& Alonso, M. (2020). Cross-National Research: Partnerships in International 552 Relations: A Study of Research Groups' Practices of MERCOSUR-- Re-envisioning Scholarly 553 Activities Beyond the Global North-Global South Divide. Journal of Studies in International 554 Education 24(1): 79-96.

555 Penders, B., and Shaw, D. M. (2020). Civil disobedience in scientific authorship: Resistance and 556 insubordination in science. Accountability in Research 1-25. 
557 Prescod-Weinstein, C. (2015). Intersectionality as a Blueprint for Postcolonial Scientific

558 Community Building. Medium. Available at https://medium.com/@chanda/intersectionality-as-a-

559 blueprint-for-postcolonialscientific-community-building-7e795d09225a\#.6ijse2h1r

560 Proctor, R. N., \& Proctor, R. (1991). Value-free science?: Purity and power in modern 561 knowledge. Harvard University Press.

562 Quintero Toro, C. (2012). Birds of empire, birds of nation: A history of science, economy, and 563 conservation in United States-Colombia relations. Ediciones Uniandes-Universidad de los

564 Andes.

565 R Core Team. R: A language and environment for statistical computing. (2013).

566 Rainforest Trust, New Bird Species Named for E.O. Wilson, "Father of Biodiversity" and

567 Rainforest Trust Board Member. https://www.rainforesttrust.org/new-bird-species-named-father-

568 biodiversity-rainforest-trust-board-member-dr-e-o-wilson. Accessed 1 May 2020.

569 Ragep, F. J. (2009). David C. Lindberg. The Beginnings of Western Science: The European

570 Scientific Tradition in Philosophical, Religious, and Institutional Context, Prehistory to ad 1450.

571 xvi+ 488 pp., figs., bibl., index. Chicago/London: University of Chicago Press, 2007.

572 Richardson, W. J. (2018). Understanding Eurocentrism as a structural problem of undone

573 science. In G. K. Bhambra, D. Gebrial, and K. Nişancıoğlu (Eds.), Decolonising the University

574 (pp. 231-247). London, Pluto Press.

575 Rigg, J. (2007). An everyday geography of the global south. Routledge.

576 Robinson, S.K., 2019. Bird niches in human culture and why they matter. Proceedings of the

577 National Academy of Sciences, 116(22), pp.10620-10622.

578 Said, E. W. (1979). Orientalism. Vintage.

579 Saini, A. (2019). Superior: the return of race science. Beacon Press.

580 Schuetz, J. G., \& Johnston, A. (2019). Characterizing the cultural niches of North American

581 birds. Proceedings of the National Academy of Sciences, 116(22), 10868-10873.

582 Shen, H. W., \& Barabási, A. L. (2014). Collective credit allocation in science. Proceedings of the 583 National Academy of Sciences, 111(34), 12325-12330.

584 Sheth, M. J. (2019). Grappling with racism as foundational practice of science teaching. Science 585 Education, 103(1), 37-60. 
586 The Malaria Expedition to West Africa (1900). Science, 11(262), 36-37.

587 Tscharntke, T., Hochberg, M. E., Rand, T. A., Resh, V. H., \& Krauss, J. (2007). Author

588 sequence and credit for contributions in multiauthored publications. PLoS biology, 5(1).

589 Valantine, H. A., Lund, P. K., \& Gammie, A. E. (2016). From the NIH: A systems approach to 590 increasing the diversity of the biomedical research workforce. CBE - Life Sciences Education 591 15(fe4), 1-5.

592 Veracini, L. (2010). Settler colonialism. Houndmills, UK: Palgrave Macmillan, 10, 5939780230299191.

594 Ward-Fear, G., Pauly, G. B., Vendetti, J. E., \& Shine, R. (2020). Authorship Protocols Must 595 Change to Credit Citizen Scientists. Trends in Ecology \& Evolution 35(3).

596 Weinstein, B. (1983). The Amazon rubber boom, 1850-1920. Stanford University Press.

597 Wynn-Grant, R. (2019). Available at

598 https://threadreaderapp.com/thread/1116076320188981250.html 